\title{
THE VALUE OF THE ACID TEST MEAL: A STUDY OF NORMAL PERSONS AND OF PERSONS WITH DUODENAL ULCER
}

\author{
BY C. STUART WELCH AND MANDRED W. COMFORT \\ (From The Mayo Foundation and the Division of Medicine, The Mayo Clinic, Rochester, Minn.)
}

(Received for publication April 5, 1938)

Much evidence has been accumulated to show that the separate secretions of the gastro-intestinal tract have a definite and invariable composition under normal conditions (1). These secretions are isotonic with blood serum; each has its own acid-base pattern. In the stomach two main fluids arise from different groups of cells. The first is a secretion of isotonic hydrochloric acid from the chief cells of the body and fundus of the stomach; the second is a slightly alkaline fluid which probably is secreted for the most part by the antral mucosa. Hydrochloric acid is secreted by the stomach in the concentration of approximately $600 \mathrm{mgm}$. of chloride for each $100 \mathrm{cc}$. (2, $3,4)$, although its concentration in mixed gastric contents may show wide variations in health and disease. Five other non-acid secretions, in addition to that elaborated by the antral mucosa, enter the stomach and thus affect the concentration of acid in the final mixture. These fluids are: saliva, pancreatic juice, bile, mucus, and intestinal juice. Pancreatic juice, bile, and intestinal juice are likewise isotonic with blood serum. The alkaline fluid secreted by the stomach and the fluids which enter the stomach from the duodenum have a tendency to reduce the concentration of isotonic hydrochloric acid in the gastric contents. This is accomplished by dilution more than it is by neutralization. The importance of the factor of neutralization will depend largely on the alkalinity as well as on the quantity of the duodenal fluid regurgitated into the stomach. On the other hand, the secretion of more isotonic hydrochloric acid by the fundic cells will tend to conteract the effect of the addition of alkaline fluids and to maintain the normal concentration of the hydrochloric acid. The concentration of hydrochloric acid in the stomach at any one time will depend on the volume and concentration of acid and alkaline material that are mixed together.

The usual gastric test meal furnishes information concerning the concentration of free hy- drochloric acid in the gastric contents after dilution and neutralization but gives little information concerning the relative amounts of acids and alkaline fluids that enter the stomach during the test period. A method of study that has been evolved by Wilhelmj, Neigus, and Hill (3) promises to furnish some information about this point. For this reason, a clinical appraisal of the method, after defining its limitations, seemed appropriate. Specifically, we were interested in ascertaining the clinical value of the method, in finding to what extent dilution, neutralization, and secretion of chloride as hydrochloric acid during the test period could be measured, in observing the influence of regurgitation of duodenal fluids on the concentration of hydrochloric acid in the test meal, and finally in contrasting the effectiveness of dilution, neutralization, and secretion of hydrochloric acid in reducing and maintaining the concentration of hydrochloric acid introduced into the intact stomach of normal persons and of patients who had duodenal ulcer. Twenty-five normal persons and thirty persons who had duodenal ulcer kindly consented to submit to this test in order that we might ascertain the clinical value of the method.

\section{METHOD}

The method (3) is fundamentally a simple one. Three hundred cubic centimeters of approximately 0.1 normal solution of hydrochloric acid that contains phenol red in the amount recommended by Wilhelmj, Neigus, and Hill (3), is placed in the stomach and allowed to remain there thirty minutes, after which time the contents of the stomach are aspirated as completely as possible. The test is repeated two or three times at one sitting. Preliminary preparation includes a fast for fifteen hours and lavage of the stomach with the test solution before the beginning of each test, in order to avoid as much as possible the effect of immediate dilution. The gastric contents are removed thirty minutes after the instillation of the test solution and are examined for the concentration of total chloride, the concentration of acid chloride (chloride as hydrochloric acid), and the concentration of phenol red. The method of Van Slyke (5) is used for estimation of total chloride. The con- 
centration of acid chloride is estimated from the concentration of free hydrochloric acid as determined by titration with a 0.1 normal solution of sodium hydroxide by using dimethylaminoazobenzene as an indicator. The concentrations are expressed in terms of milligrams of chloride per $100 \mathrm{cc}$. of gastric contents. The concentration of phenol red in the gastric contents is determined by the method outlined by Wilhelmj, Neigus, and Hill (3), and is expressed as percentage of the concentration of phenol red in the original test solution. For example, if the concentration of phenol red in the solution introduced into the stomach was 1 per cent, and the concentration of phenol red in the aspirated gastric contents was 0.5 per cent, the concentration of phenol red in this aspirated gastric contents would be expressed as 50 per cent. As will appear in the next paragraph, another subtraction remains to be made to secure the final result.

Calculation. The amount of dilution, that is, the number of cubic centimeters of various secretions which entered the stomach in the test periods per $100 \mathrm{cc}$. of gastric contents removed, can be determined by subtracting the concentration of phenol red in the aspirated gastric contents (expressed as percentage of concentration in the original test solution) from 100 . In the example, then, 50 would be subtracted from 100 and the final result is 50 , which represents the number of cubic centimeters of dilution per $100 \mathrm{cc}$. of aspirated contents.

The diluting effect of this volume of fluid on the concentration of acid in the original test solution is estimated by multiplying the concentration of acid chloride in the original test solution by the percentage of phenol red in the recovered gastric contents. This constitutes the correction for dilution. The amount of acid chloride of the test solution that has been neutralized (neutralized chloride) is determined by subtracting the concentration of acid chloride in the gastric contents from the concentration of acid chloride in the original test solution corrected for dilution. The value for the neutralized chloride may be determined only when the concentration of acid chloride, as obtained by analysis, is less than the concentration of acid chloride in the test solution corrected for dilution. The concentration of acid chloride that is effective in increasing the concentration of acid chloride in the test solution after correction for dilution is determined by subtracting the concentration of acid chloride of the original test solution, which has been corrected for dilution, from the concentration of acid chloride in the gastric contents. This value for the extra acid chloride may be determined only when the concentration of acid chloride in the gastric contents is greater than the concentration of acid chloride in the test solution which has been corrected for dilution. If it is found that the concentration of acid in the gastric contents is less than could be accounted for by physical dilution, as determined by the change in concentration of phenol red, it shows that the various secretions which entered the stomach and mixed with the test meal contained alkali in excess of acid. On the other hand, if the concentration of acid in the gastric contents exceeds the amount expected after correction for dilution, it shows, conversely, that the secretions added to the test meal contained hydrochloric acid in excess of neutralizing material. Thus, the analyses and calculations which are employed in determining the type of fluid which enters the stomach and mixes with the acid test meal depend in a large measure on the estimation of the dilution which the test meal has undergone. These calculations will be more fully considered when the clinical application of the method is reached.

THE EXTENT TO WHICH THE EFFECT OF ENTRANCE

\section{OF ALKALINE FLUID AND ACID FLUID INTO} THE STOMACH CAN BE MEASURED

The results naturally divided the tests into two groups: first, those in which more alkaline secretions than acid secretions entered the stomach, and second, those in which more acid secretions than alkaline secretions entered the stomach. Typical experiments of each type will be described.

There is ample evidence that secretions which enter a stomach that is capable of secreting hydrochloric acid and contains an acid test meal are composed of both acid and alkali. The observations of Pavlov (6), Ivy and Whitlow (7), MacLean, Griffiths, and Williams (8), MacLean and Griffiths $(9,10)$, Apperly (11), and Apperly and Norris (12) have demonstrated that acid secretion is inhibited when $\mathrm{N} / 10$ solution of hydrochloric acid is placed in the stomach, but the observations of Apperly and Norris (12), and Wilhelmj, O'Brien, and Hill (13) clearly demonstrate that the acid test meal does not always or completely inhibit the secretion of acid by the stomach. Apperly and Norris found that in a small percentage of cases hydrochloric acid was secreted after the introduction of 0.08 normal to 0.128 normal solutions of hydrochloric acid, and Wilhelmj, O'Brien, and Hill demonstrated that the secretion of hydrochloric acid by the gastric mucosa of dogs was not completely inhibited by a 0.1 normal solution of hydrochloric acid. In previous clinical studies in which the acidity of the gastric contents was determined by using the acid test meal $(14,15,16)$, the contrary has been assumed, namely, that the introduction of an approximately 0.1 normal solution of hydrochloric acid completely inhibited the secretion of hydrochloric acid by the stomach. Similarly, evidence may be cited that alkaline fluid usually, if not al- 
ways, enters the stomach when it contains an acid test meal. First, bile pigments frequently are present in the gastric contents, but the absence of bile pigments does not necessarily indicate an absence of duodenal regurgitation. Spencer, Meyer, Rehfuss, and Hawk (17) demonstrated that a tryptic enzyme is almost constantly present in the digestive contents of the normal stomach and concluded that the trypsin was regurgitated from the duodenum. Medes and Wright (18) have likewise demonstrated that duodenal regurgitation without bile pigment is a frequent occurrence. Second, Wilhelmj, Henrich, Neigus, and Hill (4), by using the acid test meal, showed that antral secretion into the stomach of dogs is continuous and that the volume secreted in thirty minutes varies from 2 to $15 \mathrm{cc}$. and is apparently independent of the amount of acid secretion. The results of our experiments demonstrate that secretions which enter an intact stomach that is capable of secreting hydrochloric acid, during the thirty-minute period, are composed usually, if not always, of both acid and alkali. Obviously, this is not true if the stomach is unable to secrete hydrochloric acid.

Changes in concentration caused by the entrance of more alkaline secretions than acid secretions. An acid solution which has a concentration of
$358 \mathrm{mgm}$. of acid chloride per $100 \mathrm{cc}$. was introduced into the stomach of Subject 1 at the beginning of the first test period (Table I). After thirty minutes, the solution contained phenol red in a concentration of only 73 per cent of the original concentration. In other words, $27 \mathrm{cc}$. of fluid per $100 \mathrm{cc}$. of contents had entered the stomach during the test period. If this fluid had been water the concentration of acid chloride in the contents removed at the end of the test period would have been $261 \mathrm{mgm}$. per $100 \mathrm{cc}$. and the concentration of acid chloride in the original acid solution would have been reduced $97 \mathrm{mgm}$. per $100 \mathrm{cc}$. Actually, however, the concentration of acid chloride in the original acid solution was reduced not 97 mgm., but 124 mgm. per 100 cc., and the concentration of acid chloride in the gastric content was not 261 but $234 \mathrm{mgm}$. per 100 cc. The reduction in concentration was greater than that expected from dilution alone, and a further reduction of acid concentration resulted from neutralization. Three-fourths (97 mgm.) of the reduction in concentration of acid chloride introduced into the stomach as a test solution was accomplished by the factor of dilution and a fourth (27 mgm.) was accomplished by neutralization. The proportion of the reduction due to dilution and to neutralization is similar to that shown by Wil-

TABLE I

Results of tests performed on three normal persons

\begin{tabular}{|c|c|c|c|c|c|c|c|}
\hline & \multicolumn{2}{|c|}{ Subject 1} & \multicolumn{2}{|c|}{ Subject 2} & \multicolumn{3}{|c|}{ Subject 3} \\
\hline & \multirow{2}{*}{ Test 1} & \multirow{2}{*}{ Test 2} & \multirow{2}{*}{ Test 1} & \multirow{2}{*}{ Test 2} & \multicolumn{2}{|c|}{$\begin{array}{l}\text { Before administra- } \\
\text { tion of secretin }\end{array}$} & \multirow{2}{*}{$\begin{array}{c}\begin{array}{c}\text { After adminis- } \\
\text { tration of } \\
\text { secretin }\end{array} \\
\text { Test } 3\end{array}$} \\
\hline & & & & & Test 1 & Test 2 & \\
\hline 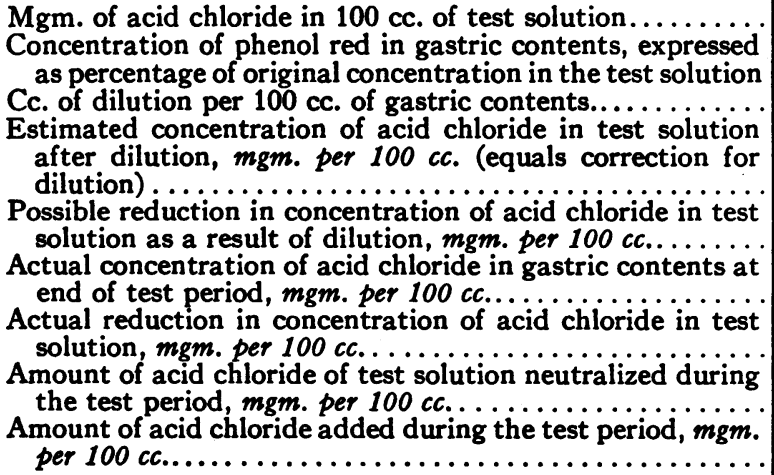 & $\begin{array}{r}358 \\
73 \\
27 \\
\\
261 \\
97 \\
234 \\
124 \\
27\end{array}$ & $\begin{array}{r}358 \\
66 \\
34 \\
\\
236 \\
122 \\
197 \\
161 \\
39\end{array}$ & $\begin{array}{r}342 \\
49 \\
51 \\
168 \\
174 \\
326 \\
16 \\
158\end{array}$ & $\begin{array}{r}342 \\
40 \\
60 \\
137 \\
205 \\
292 \\
50 \\
155\end{array}$ & $\begin{array}{r}364 \\
68 \\
32 \\
248 \\
116 \\
246 \\
118 \\
2\end{array}$ & $\begin{array}{r}364 \\
63 \\
37 \\
\\
229 \\
135 \\
239 \\
125\end{array}$ & $\begin{array}{r}364 \\
52 \\
48 \\
\\
189 \\
175 \\
88 \\
276 \\
101\end{array}$ \\
\hline
\end{tabular}


helmj, Henrich, and Hill (19) when mixed duodenal secretions were added to acid gastric contents, and suggests that very little acid entered the stomach during the test period. The results obtained in the secorid test which was carried out on Subject 1 during the thirty-minute period following the conclusion of the first thirty minutes (Table I) are practically identical with those obtained in the first test.

It should be clearly understood that the $27 \mathrm{mgm}$. of acid chloride neutralized were milligrams of acid chloride per $100 \mathrm{cc}$. of the original acid solution and that these $27 \mathrm{mgm}$. per $100 \mathrm{cc}$. of the original acid test solution probably do not represent all the acid chloride neutralized by the alkaline fluid that entered the stomach during the test period. It is most important to note that any acid chloride secreted during the thirty-minute period was likewise neutralized as well as the 27 mgm. of acid chloride per $100 \mathrm{cc}$. of the test solution. The method does not permit measurement of this fraction of neutralization or of the total neutralization that occurs during the test period. On the other hand, the $124 \mathrm{mgm}$. reduction in the concentration of acid chloride in each $100 \mathrm{cc}$. of the test fluid is the net result of the reduction of concentration by dilution and neutralization and of the increase in concentration caused by the entrance of pure acid gastric juice that contains acid chloride in a concentration greater than the concentration in the test solution (approximately $600 \mathrm{mgm}$. per $100 \mathrm{cc}$.). The reduction in concentration in this case is probably not a true measure of all the dilution and neutralization which the alkaline fluid that enters the stomach is capable of producing but is a measure of dilution and neutralization after neutralization of the acid chloride secreted by the stomach.

The results of Tests 1 and 2 on Subject 1 (Table I) are typical of the results of tests performed when fluid that enters the stomach contains little acid and is predominantly alkaline: The results of Test 1 on Subject 3 , on the contrary, are typical of the results obtained when only slightly more alkaline than acid material is present in the fluid that enters the stomach. If the results of this test are analyzed in a manner similar to that in which Tests 1 and 2 on Subject 1 were analyzed, it will be found that the same conclusions may be drawn. In other words, so long as the alkaline elements predominate over the acid elements in the combined fluids that enter the stomach during the test period, whether the predominance be great or small, the method permits measurement of reduction in concentration of acid chloride in the test fluid by dilution and measurement of reduction in concentration caused by neutralization. The reduction in concentration caused by dilution is always 100 per cent while that caused by neutralization varies from a negligible amount to as much as a fourth of the total reduction. The method does not permit, under these circumstances, a measurement of the acid secreted and neutralized or an estimation of the total neutralization that occurs during the test period.

Changes in concentration caused by the entrance of more acid fluid than alkaline fluid. A solution containing acid chloride in a concentration of 342 mgm. per $100 \mathrm{cc}$. was introduced into the stomach of Subject 2 at the beginning of the first test period (Table I). The percentage of the original concentration of phenol red in the gastric contents recovered after thirty minutes was 49 . In other words, the volume of fluid which entered the stomach, per $100 \mathrm{cc}$. of gastric contents, during this period was $51 \mathrm{cc}$. If the fluid which entered the stomach had been water, the concentration of chloride in the gastric contents recovered after thirty minutes would have been 168 mgm. per $100 \mathrm{cc}$. and the original concentration of acid chloride would have been reduced by 174 mgm. per 100 cc. ( 51 per cent). Actually, the concentration of acid chloride in the gastric contents recovered at the end of thirty minutes was much greater (326 mgm. per $100 \mathrm{cc}$.) and the actual reduction in concentration was only 16 mgm. The results obtained in Test 2 , which was carried out on Subject 2 during the second thirtyminute period, are practically identical with those of Test 1.

The reduction in concentration of acid chloride in the test solution was only 9.2 per cent of the reduction that would have been accomplished had the fluid which entered the stomach been water; moreover, no neutralization of the test solution was measurable. Instead, at least $158 \mathrm{mgm}$. of acid chloride per $100 \mathrm{cc}$. of test solution had been added during the test period. Undoubtedly, some 
neutralization occurred but the amount of acid chloride neutralized is unknown.

Approximately $26 \mathrm{cc}$. of pure fundic acid secretion per $100 \mathrm{cc}$. of gastric contents is sufficient to add $158 \mathrm{mgm}$. of acid chloride per $100 \mathrm{cc}$. of gastric contents. The $51 \mathrm{cc}$. of fluid, per 100 cc. of gastric contents, that entered the stomach contained not only $26 \mathrm{cc}$. of pure acid chloride secretion and added not only $158 \mathrm{mgm}$. per 100 cc. of acid chloride but also added additional acid chloride that was sufficient to neutralize all the alkali in the remaining $25 \mathrm{cc}$. of combined fluid that entered the stomach. The $158 \mathrm{mgm}$. of acid chloride does not represent the total amount of acid chloride added during the test period but represents only that part of the added acid chloride calculable after neutralization of the alkali in the combinied fluids that entered the stomach. The amount of acid chloride neutralized is not measurable by the method.

Tests 1 and 2 on Subject 2 are typical of tests in which more acid material than alkaline material is present in the fluid that enters the stomach during the test period. The same is true of Test 2 on Subject 3. In Tests 1 and 2 on Subject 2 the acid material is greatly in excess of the alkaline material, whereas in Test 2 on Subject 3 the acid material is only slightly in excess of the alkaline material. If the results of Test 2 on Subject 3 are analyzed as were results of Test 1 on Subject 2, the same conclusions may be reached. In other words, whenever the acid material predominates over the alkaline substance in the combined duodenal and gastric fluids that enter the stomach, the method measures reduction in concentration of acid chloride in the test fluid, reduction in the concentration caused by dilution, and the predominance of acid chloride over alkali in the combined solutions that enter the stomach. The reduction in concentration of the test solutions is less than that expected from the addition of water alone and may be accounted for by the factor of dilution. Neutralization does not reduce the concentration of acid chloride in the test solution. The method permits measurement of only part of the acid chloride secreted during the test period; it does not permit measurement of the alkali that enters the stomach or measurement of the extent of neutralization of acid that enters the stomach.

\section{COMMENT}

Regardless of the type of fluid that enters the stomach the method permits measurement of the excess of alkali or acid in the combined fluids that enter the stomach. When the fluid is predominantly alkaline, the excess of alkali over acid in the combined fluids that enter the stomach is measured. When the fluid is predominantly acid, the excess of acid over alkali is measured.

When the combined secretion that enters the stomach contains more alkali than acid the combined secretions dilute the test solution as much as water, dilution is 100 per cent effective, the combined secretions neutralize some of the test solution, and the reduction in concentration of the acid chloride of the test solution is caused both by dilution and neutralization. The reduction in concentration of acid chloride of the test solution is the measure of the effect of dilution and neutralization on the test fluid, after neutralization of all acid chloride secreted by the stomach.

When the combined secretions that enter the stomach contain more acid than alkali, the combined secretions dilute the test solution less than water. That is, dilution is less than 100 per cent effective. The combined fluids do not neutralize any of the acid chloride in the test solution. The combined secretions add acid chloride to the test solution, and thus tend to maintain the original concentration of acid chloride that is introduced into the stomach. The reduction in concentration of test solution may be accounted for entirely by the factor of dilution.

The reduction in the concentration of test solution is the net result of dilution and neutralization on the one hand and the addition of acid chloride on the other. Dilution is 100 per cent effective so long as the alkaline substances in the test fluid are greater than the acid substances. Dilution is less effective as the proportion of acid fluid in the total fluid that enters the stomach becomes greater.

At the beginning of this analysis of the method, we cited evidence that the introduction of acid chloride in a concentration of approximately 0.1 normal did not always inhibit completely the secretion of acid by the stomach during the test period. In this connection it should be noted that the acid chloride secreted by the stomach was 
measurable in 40 per cent of the tests on normal persons and in 84 per cent of the tests on persons who had duodenal ulcer (Table II). Certainly,

TABLE II

Results obtained when acid test meals were administered to normal persons and to patients who had duodenal ulcer

\begin{tabular}{|c|c|}
\hline $\begin{array}{c}\text { Normal } \\
\text { persons } \\
(30 \text { tests })\end{array}$ & $\begin{array}{l}\text { Persons who had } \\
\text { duodenal ulcer } \\
\text { (38 tests) }\end{array}$ \\
\hline $\begin{array}{l}\text { Cubic centimeter of dilution } \\
\text { (average) per } 100 \text { cc. of gas- } \\
\text { tric contents............ } 23 \\
\text { Average reduction in concen- } \\
\text { tration of acid chloride, } \\
\text { mgm. per } 100 \text { cc............ } \\
\text { Percentage of cases in which } \\
\text { there was a demonstrable } \\
\text { neutralization of acid chlo- } \\
\text { ride in test solution......... } 60 \\
\text { Percentage of cases in which } \\
\text { there was an increase in } \\
\text { concentration of acid chlo- } \\
\text { ride, after correction for } \\
\text { dilution................... } 40\end{array}$ & 16 \\
\hline
\end{tabular}

in about 65 per cent of our experiments acid chloride was secreted by the stomach during the test period in spite of the introduction of 0.1 normal solution of hydrochloric acid. The inhibition of acid secretion by the introduction of a solution of 0.1 normal hydrochloric acid into the stomach was much less in the cases of duodenal ulcers than it was among normal persons.

The effect of increasing the amount of alkaline fluid that enters the stomach during the test period on dilution and neutralization. We found that regurgitation of the duodenal contents often follows the intravenous injection of secretin or decholin. In this way we were able to produce regurgitation and study the effect of regurgitation of the test meal in the intact human stomach.

In Tests 1 and 2 on Subject 3 (Table I), 32 and $37 \mathrm{cc}$. of combined duodenal fluid and gastric fluid entered the stomach during the test meal and reduced the concentration of the acid chloride of the test solution 118 and $125 \mathrm{mgm}$., respectively. In Test 1, $2 \mathrm{mgm}$. of acid chloride of the test solution was neutralized, while in Test 2 , $10 \mathrm{mgm}$. of extra acid chloride per $100 \mathrm{cc}$. of gastric contents was added. 'In other words, the factors that regulate acidity of the gastric contents acted similarly on the concentration of the acid test meal in the two tests. Dilution was about 100 per cent effective, neutralization was negligible, and the acid material and alkaline material in the fluids that entered the stomach were approximately equal. At the beginning of the third consecutive thirty-minute test period, $30 \mathrm{mgm}$. of purified secretin was administered intravenously. During the third test period, an increased amount of fluid ( $48 \mathrm{cc}$. instead of about $35 \mathrm{cc}$.) entered the stomach. The reduction in concentration of acid chloride in the test fluid increased from about $120 \mathrm{mgm}$. to $276 \mathrm{mgm}$. per $100 \mathrm{cc}$. of test solution. After the administration of secretin and after regurgitation had occurred, dilution reduced the concentration of acid chloride $175 \mathrm{mgm}$. instead of about $120 \mathrm{mgm}$. per $100 \mathrm{cc}$. of test fluid and was 100 per cent effective just as it was before the administration of secretin and before regurgitation; neutralization became definitely effective and reduced the concentration of the acid chloride in the test solution about $101 \mathrm{mgm}$. per $100 \mathrm{cc}$., and the alkaline material markedly predominated over the acid material in the fluid that entered the stomach. It should be noted especially that the total reduction in the concentration of acid chloride of the test solution was affected 63 per cent instead of approximately 100 per cent by dilution after regurgitation was induced, and 37 per cent instead of 0 per cent by neutralization after regurgitation was induced.

In this experiment the amounts of acid material and alkaline material in the combined fluids that entered the stomach during the preliminary test periods were approximately equal; following the administration of secretin, additional alkaline fluid entered the stomach, the amount of acid became definitely less than the alkaline material in the combined fluids that entered the stomach, the concentration of acid chloride in the test solution was reduced beyond the reduction seen during the preliminary periods, the reduction caused by dilution was materially increased, and neutralization, which either was not measurable or was measurable to only a slight extent during preliminary tests, became measurable and accounted for approximately 37 per cent of the total reduction in concentration of the acid chloride in the test solution. In other experiments in which the amount of acid was routinely greater than the alkali in the combined fluid that entered the stomach during the 
preliminary test periods, the regurgitation of alkaline fluid was sufficient to reverse the ratio of acid to alkaline material in the combined fluids, to render dilution 100 per cent effective, and to increase neutralization, which was not measurable in the preliminary test periods, to the point where it was measurable and accounted for a considerable portion of the total reduction in the concentration of acid chloride in the test solution. Such experiments clearly show the effectiveness of duodenal fluid in reducing the concentration of hydrochloric acid in the gastric contents and demonstrate that the reduction is accomplished chiefly by dilution and to a lesser extent by neutralization, as it is in dogs (19).

A comparison of factors of dilution and neutralization with the factor of acid secretion in normal persons and in cases of duodenal ulcer. The acid test meal was administered on thirty occasions to normal subjects and on thirty-eight occasions to patients who had duodenal ulcer. The data in Table II show interesting but contrasting tendencies in the action of the factors that regulate the acidity of the gastric contents in the two groups. An average of $33 \mathrm{cc}$. of fluid per $100 \mathrm{cc}$. of gastric content entered the stomachs of the patients who had duodenal ulcer and an average of $23 \mathrm{cc}$. of fluid entered the stomachs of normal persons; that is, the average amount of fluid that entered the stomachs of persons who had duodenal ulcer was greater by $10 \mathrm{cc}$. than the average amount of fluid that entered the stomachs of normal persons. The average reduction in the concentration of acid chloride in the test solution was $67 \mathrm{mgm}$. per $100 \mathrm{cc}$. for the group of persons who had duodenal ulcer and $76 \mathrm{mgm}$. per $100 \mathrm{cc}$. for the group of normal persons; that is, the average reductions in concentration were less by $9 \mathrm{mgm}$. per $100 \mathrm{cc}$., or 12 per cent, for the group of patients who had duodenal ulcer than it was for the group of normal persons.

This combination of findings, that is, the fact that more fluid entered the stomachs and less reduction occurred in the concentration of acid chloride in the test solution in cases of duodenal ulcer than occurred among normal persons, means that, on the average, more pure acid secretion entered the stomachs of the patients who had duodenal ulcer than entered the stomachs of normal persons. This is in conformity with the well- recognized fact that patients who have duodenal ulcer on an average secrete a larger volume of highly acid fluid following stimulation with histamine than do normal persons.

Neutralization of the acid chloride of the test solution was measurable in 60 per cent of the group of normal persons, but in only 16 per cent of the group of persons who had duodenal ulcer. Again, while acid chloride secreted by the stomach (extra acid chloride) was measurable in only 40 per cent of the group of normal persons it was measurable in 84 per cent of the group of persons who had duodenal ulcer. We have just pointed out that neutralization of acid chloride of the test solution is measurable by this method only when alkali exceeds acid, and acid chloride secreted by the stomach is measurable only when acid chloride exceeds alkali in the fluids that enter the stomach during the test period. In other words, while the alkali exceeds the acid chloride in the fluid that enters the stomach during the test period in about four times as many normal persons as it does in persons who have duodenal ulcer, acid chloride exceeds alkali in about five times as many persons who have duodenal ulcer as it does among normal persons. Since dilution is 100 per cent effective so long as alkaline material exceeds acid material in the fluid that enters the stomach, it will be seen that dilution was 100 per cent effective among 60 per cent of normal persons, but in only 16 per cent of persons who had duodenal ulcer. Dilution is usually much more effective among normal persons than it is among persons who have duodenal ulcer.

The greater average reduction that occurred in the concentration of acid chloride in the test solution in the case of normal persons results from the greater frequency with which alkali exceeds acid in the fluid that enters the stomach and consequently from the greater effectiveness of neutralization and dilution in the case of normal persons. Elman (15), on the basis of data obtained while using the acid test meal on dogs, and Levy (16), on the basis of data obtained while using the acid test meal on man, concluded that the smaller reductions of concentration in acid chloride in the test solution in cases of duodenal ulcer was attributable to an actual deficiency in neutralization. In order to reach such conclusions from the experimental data, these authors assumed 
that introduction of a solution of approximately 0.1 normal hydrochloric acid inhibits the secretion of acid chloride by the stomach during the test period and therefore that the reduction in concentration of the chloride in the test solution represents the influence of neutralization and dilution unaffected by the secretion of acid. The conception that the introduction of approximately 0.1 normal solution of hydrochloric acid would always completely inhibit the secretion of acid chloride by the stomach during a thirty-minute test period has been rather well disproved by the work of Apperly and Norris (12) and Wilhelmj, O'Brien, and Hill (13). The findings in our own experiments cast still further doubt on the validity of this conception. Our findings demonstrate that hydrochloric acid was definitely secreted in 65 per cent of cases, that it probably was secreted even in a great majority of the remaining cases, and that a 0.1 normal solution of hydrochloric acid will not always completely inhibit the secretion of hydrochloric acid. They also demonstrate that the reduction of concentration of acid chloride in the solution used as a test meal cannot be explained solely on the basis of variations in the amount of alkaline fluid that enters the stomach but that it is chiefly dependent on the degree of preponderance of the factor of dilution and neutralization over the factor of acid secretion.

While there is a relative deficiency of alkali in cases of duodenal ulcer we have been unable to find conclusive evidence that there is an actual decrease in the amount of alkali that enters the stomachs of patients who have duodenal ulcer, although we suspect this is so. The work of Elman and Rowlette (20), which demonstrated that pyloric obstruction that was produced experimentally increases the acidity of the gastric contents of dogs, may be cited in support of the belief that the pylorospasm and the organic obstruction in duodenal ulcer reduce regurgitation and result in an increase in the concentration of hydrochloric acid in the gastric contents as a result of a decrease in the effectiveness of neutralization.

\section{SUM MARY}

The acid test meal that contains phenol red as an indicator of dilution provides an excellent method for studying the factors which regulate acidity of the gastric contents, and demonstrates the interplay of dilution and neutralization on the one hand and of acid secretion on the other. The method permits measurement of the reductions of the concentration of acid chloride in the test fluid during the test period, of the excess of acid or alkaline material in the combined fluids that enter the stomach, and of the effectiveness of the factor of dilution. The method has certain limitations. It does not permit measurement of the total amount of acid secreted, of the total amount of alkali that enters the stomach, or of the total neutralization of acid chloride during the test period. It is an excellent method for the clinical demonstration of effectiveness of duodenal regurgitation in reducing acidity of the gastric contents and it demonstrates that this reduction is partly attributable to dilution and partly to neutralization. Increased regurgitation of duodenal fluid has again been shown to be an effective means of reducing acidity of the gastric contents, a fact long recognized and applied surgically in many operations designed for the treatment of peptic ulcer. Regurgitation increases the reduction attributable to both dilution and neutralization. The relative importance of the factors concerned in the regulation of acidity of the gastric contents is different in the case of normal persons and in cases of duodenal ulcer. The alkaline elements are greater than the acid elements in the fluids entering the stomachs of a majority of normal persons, whereas the reverse holds true in a majority of patients who have duodenal ulcer. As a result of this fundamental difference, dilution tends to be 100 per cent effective in the case of normal persons while this is rarely so in cases of duodenal ulcer. Moreover, neutralization of the acid chloride of the test solution is usually measurable among normal persons but occurs rarely in cases of duodenal ulcer. The acid secreted by the fundic cells appeared to have a greater average volume in cases of duodenal ulcer than it did in the group of normal persons studied. While there is good evidence that there is a relative deficiency of alkali in the fluid that enters the stomach of patients who have duodenal ulcer, the method does not permit a statement that there is an actual deficiency. 


\section{BIBLIOGRAPHY}

1. Peters, J. P., Body Water: The Exchange of Fluids in Man. Charles C. Thomas, Springfield, 1935.

2. Hollander, Franklin, and Cowgill, G. R., Studies in gastric secretion. I. Gastric juice of constant acidity. J. Biol. Chem., 1931, 91, 151.

3. Wilhelmj, C. M., Neigus, Irwin, and Hill, F. C., Studies on the regulation of gastric acidity. I. The influence of acid on the secretion of hydrochloric acid by fundic pouches and by the whole stomach. Am. J. Physiol., 1933, 106, 381.

4. Wilhelmj, C. J., Henrich, L. C., Neigus, Irwin, and Hill, F. C., The chloride concentration of gastric secretion from fundic pouches and from the intact whole stomach. Am. Jour. Physiol., 1934, 108, 197.

5. Van Slyke, D. D., The determination of chlorides in blood and tissues. J. Biol. Chem., 1923, 58, 523.

6. Pavlov, I. P., The Work of the Digestive Glands. Charles Griffin and Co., London, 1910, 2d ed.

7. Ivy, A. C., and Whitlow, J. E., The gastrin theory put to physiological test. Am. J. Physiol., 1922, 60, 578.

8. MacLean, Hugh, Griffiths, W. J., and Williams, B. W., Variations in the acidity and total chloride contained in the secretion from an isolated Pavlov pouch in the dog. J. Physiol., 1928, 65, 77.

9. MacLean, Hugh, and Griffiths, W. J., The automatic regulation of gastric acidity. J. Physiol., 1928, 66, 356.

10. MacLean, Hugh, and Griffiths, W. J., The factors influencing the concentration of hydrochloric acid during gastric digestion. J. Physiol., 1928, 65, 63.
11. Apperly, F. L., Duodenal regurgitation and the control of the pylorus. Brit. J. Exper. Path., 1926, $7,111$.

12. Apperly, F. L., and Norris, J. H., The automatic regulation of gastric acidity. J. Physiol., 1930, $70,158$.

13. Wilhelmj, C. M., O'Brien, F. T., and Hill, F. C., The inhibitory influence of the acidity of the gastric contents on the secretion of acid by the stomach. Am. J. Physiol., 1936, 115, 429.

14. Apperly, F. L., Gastro-enterostomy; observations on its mechanism and on the production of pain in duodenal ulcer. M. J. Australia, 1924, 1, 256.

15. Elman, Robert, The behavior of gastric acidity in duodenal ulcer and pyloric obstruction before and after gastro-enterostomy. Surg., Gynec., and Obst., 1929, 49, 34.

16. Levy, J. S., The value of a neutralization test of gastric acidity in patients with duodenal ulcers and so-called pylorospasm. Ann. Int. Med., 1934, 7,1244 .

17. Spencer, W. H., Meyer, G. P., Rehfuss, M. E., and Hawk, P. B., Gastro-intestinal studies. XII. Direct evidence of duodenal regurgitation and its influence upon the chemistry and function of the normal human stomach. Am. J. Physiol., 1915, 39, 459.

18. Medes, Grace, and Wright, C. B., Studies on duodenal regurgitation. I. J. Clin. Invest., 1928, 6, 403.

19. Wilhelmj, C. M., Henrich, L. C., and Hill, F. C., The influence of duodenal secretions on acid gastric contents. Am. J. Physiol., 1935, 111, 293.

20. Elman, Robert, and Rowlette, A. P., The rôle of the pyloric sphincter in the behavior of gastric acidity. Arch. Surg., 1931, 22, 426. 